\title{
Views on Value of Gold
}

\section{Harshad Dave}

Additional General Manager (Retd.), Gujarat State Fertilizers and Chemicals Ltd. (GSFC), Vadodara, Gujarat, India

\begin{abstract}
Generally people and even economist use word value of gold. It is erroneous use. The status of feeling value in gold has prime six reasons and mostly the influence of gold on the human mind is due to its assured exchange value, otherwise there are few needs that might be satisfied directly by gold or its chemical compositions. The potential of status of gold is founded on the prime six reasons and it constitutes trust in assured exchange value (not value) that ultimately becomes a hope of satisfying various needs of a man. A big catastrophic collapse of social systems automatically makes gold valueless, this is proved by history also, and it is the proof of its dependency on exchange value as well as inevitability of social system. A hungry man who finds value in bread in his hand, even if he is exclusively alone on this planet earth. While a man with gold coin needs at least one more person on earth and in his association to sense so called value in the coin. That is the difference one should try to understand before using word value for gold while explaining critical topics of economics. The gold has sound foundation of history and its prestige is also evolved with evolution of human society. Not only that, but gold has ruled man with its potential of influence. However, man has faced occasions and events that convinced him about futile impression of value in gold that he carried throughout his life till date. Most tragic reality is that people are not with clarity why we sense value in gold and why the same value becomes absurd in some situation or circumstances. It is tried here to reveal some facts and realities responsible for the dilemma of the people.
\end{abstract}

Keywords: Common Human Weakness, CHW, value, exchange value.

JEL Classification: A13, A14, B21, F43, F50, I24, O12, P16, P26, P48, Z13.

(C) The Author, 2017. This article is published with open access at ARMG Publishing.

\section{Introduction}

Gold is considered to be a precious metal. It is valuable for all those who reside in human society in general. This fact cannot be over looked. If it is true that almost all the members of society find value in gold, the fact has a potential of an influence and should not be ignored. However, a philosopher in economics may not necessarily agree with the same. It might be explained with some different perceptions. In fact gold has no value, but it has exchange value. "Existence of human society" is an inevitable pre-condition to retain exchange value in gold.

If we drop a man with few gold coins with him on a lonely island where he has to manage his food and shelter by hunting and fishing and preparing hut to live in, there is no difference between pebbles on the island and gold coins with him. Then a question puzzles "Why the person lost sense of value in the gold coins?" It is not absurd to say that there must be minimum two persons on this planet earth to find value (in fact it is exchange value) in gold, otherwise, gold has no value. But it is not the case with banana. A banana does not need second person to retain value in it. If a person with gold coins goes to a primitive society in the Jungle of Congo (Africa), what he might receive in exchange of the coins there in the society in Congo, will be different than that of there in UK and still different in the society of Eskimos. This difference induces us to think over the nature of value in gold. Here, I have tried to make readers of this article aware of understanding the fact that there is a difference between value and exchange value. Value is never an exchange value. The constitution of value and that of exchange value are completely different. If the general people use the word value for gold, it does not make any difference. But, it is mandatory for the scholars of economics (economists) to know that gold has no value but what we talk of and sense in gold is its assurance of exchange value. It is the experience of people and a lesson from events of history that gold losses its value when system of the society gets jeopardized. We are going to discuss and investigate the prime causes for the same here in this article. 


\section{Looking into prime reasons}

Now I put my views as follow, the potential of exchange value of gold cannot be under estimated. It might prove to be more influential than value itself.

NB: If you ask any person why he should select a gold coin against a piece of a stone, his reply would be simple and plain..."gold is valuable". It is true for the people living outside the field of economics, but the same needs scrutiny by economists. In most of the cases, to whom we address "value of gold" is in the sense of "exchange value of gold". I contemplated on the value of gold (in fact exchange value of gold) to work out the influencing parameters that supports the present status of exchange value of gold. There are six prime parameters listed bellow and scholars of economics may ponder on it and find out any more if missed by me.

Gold has exchange value that is founded on following parameters,

[1] Human sentimental weakness (Common Human Weakness, in short CHW)

[2] Available quantities in nature and subsequently in our social system

[3] Innocent and favourable characteristics

[4] Long associations with man since ancient time or before

[5] Easy to recognize and simple ways for quality judgement

[6] Recognition in almost all the part of the world where human spices inhabits

We shall discuss above six points in detail.

\section{Human sentimental weakness}

An animal that has endless need is no one but man. If it is the same case with other animals, we do not know today. Wildlife will convince us that most of the animals devote their time managing for food, water, shelter, rest, reproduction activities, other biological activities, and defensive or offensive movements only. They do find some time out of above activities. They pass such time interacting with the surrounding natural infrastructure only. For example horse/donkey rolls over dust and sand. Wild buffalo enjoys in mud pool and crocodile seating on the river bank enjoys sun bath etc. But, human society has provided a social system supported by institutions, technology, science and many more things. This system made above activities very simple, easy and with plenty of realization opportunities. The assurance of food, shelter, sex-reproduction and defence etc has offered men exceptional opportunity to devote for their other needs irrespective of their (of needs) justification, merit or quality.

The social system offered man an opportunity to satisfy sentiments also. Otherwise, it is a matter of research to determine if animals have sentiments or not. Even if they have sentiments, as they scarcely find time out of efforts being made for the survival only, they cannot have opportunity to satisfy the same. But, unfortunately we have this opportunity in our human society and that brings odds and evens to us.

Every man in this world has one common weakness. It is a sentiment or an ardent desire "To get distinguished from others in a way that it should create dominating impression of him on others." Leaving some exceptional cases, all most all the men are victims of this weakness. It is natural law that any one might be regulated or controlled easily through his weakness. It seems to be the most economical option. Even, nature has adopted the same rout if one sharply observes the wild life documentary. Perhaps, that is the reason why one always wants to impress upon other. This most common and assured weakness has remained in man since millions or more years. This has established an instinct heritage resulting into a common culture in all. We observe this weakness in ourselves or in others living around us. Also, if we study the history of different society, the ardent thirst -"to get distinguished from others" or "becoming popular personality"- is the most common character in all most all the men/women to impress people living and remaining in their touch. Let us name this weakness as "CHW" (Common Human-Weakness). We shall use it (CHW) in further write up with above described meaning and sense.

Whenever the phrase CHW is used, it means a weakness like-"People have fervent affinity towards satisfying the desire to have something that is scare for others and distinguishing them from others". He has desire to possess something that impresses others and distinguishes him from others. CHW of a king of an imperial society and that of a king of primitive habitation in Congo might induce both the kings differently to satisfy their sentiments. However, the common fact is that both are having CHW. One might have precious stones in 
his crown, while other might decorate him with feathers of a peacock. One might seat on a snow-white marble throne covered with silky cushions, while other might seat on a big rough stone or on a log decorated with a set of horns of wild beast. Here both have ability to be there on the position and the distinguishing decoration helps him in his liabilities for ruling.

Further to this, it is interesting to note that the affinity towards becoming distinguishing personality is equally rests also in all those seating in audience in front of them. They all are with CHW and see the dreams of becoming distinguishing personality. However, each one attempts to satisfy it on opportunity or as per his self-capacity. CHW is always there in all the men \& women. Whether presence of CHW is a credit or a discredit is immaterial but its presence in all human being is an important fact. The men remained aware of this fact at every socio economics formation of society either consciously or instinctively since the primitive stage. Though, one (himself) is a victim of the $\mathrm{CHW}$, at the same time, he is aware of this characteristic in others. The ardent need in the mind of each member of the society to get distinguished from others is not a simple or trifle fact.

A person, leaving his subject $\mathrm{CHW}$ at side, does posses various other abilities also. He might have effective role and influence on the society where he makes his living or he might have moderate labour or intellectual potential. The affinity, to get distinguished from others, induces man to devote labour, time and other valuables earned by him just to satisfy the CHW. This ardent affinity, restlessly occupying his mind, creates his preparedness to sacrifice his hard earned valuables for such things that might distinguish him from others. In short, apart from having $\mathrm{CHW}$, he is otherwise a member of the society with various effective abilities, skill and other potentials. He earns for his living with the help of all these abilities, potential characteristics. This earning might be in terms of commodities, physical substances of some use value, social influence and well wish of others for him etc. The quantity of all the earnings may not be just necessary for his survival. If it is surplus one against the requirement necessary for just making his living, he would be in market to get balance saved earnings exchanged with such things that might satisfy his CHW. Even if I say that some people are so anxious to satisfy his CHW that they prefer to let go satisfaction of some important needs and divert their resources to get CHW satisfied with the same saved resources, I am not wrong.

Before I go further in this discussion, I would like to clarify two vital points to avoid confusion.

[1]. When I say that gold has no value but it does have exchange value, reader should understand the statement is in over all use and consideration of gold in human society. I do agree that there are some chemical compositions derived from gold and that are used for drug and medicine. Gold is a most ideal conductor of electricity and frequently used in electrical circuits and gadgets of critical nature. It is also used in electrical set up in ships that has to remain only in sea weather all the time. For all such usages, we may apply our perceptions of use value and value that we discussed in the article "Constitution of Value".

[2]. Apart from above discussed direct use of gold and its various compositions, gold has tremendous influence on economical transaction, market and social system as a whole. We are more interested to find out the grass root reasons and parameters that support this particular standard of gold. That is why I have not commented on other usages.

Let us come back to our discussion. Now, the above-discussed situation might be put as follow,

(A) All the members of the society (men/women) have CHW.

(B) They also have various abilities; they also have surplus resources on hand to spend for satisfying CHW.

(C) Each member of the society is aware of the above facts either consciously or instinctively.

If one studies the above three facts simultaneously in a society, at any socio economic formation level, at any place, he will realize that a person with the surplus on hand and victim of CHW is the easiest prey for others in the same society to make their (others) living. The market of cosmetics, introduction of new fashions and style, costly casino, expensive club and restaurants, luxurious travel in high class, living in posh residential area, interior decoration, expensive party-gathering, membership of highly expensive social body etc all are the live examples where satisfaction of CHW harbours in the foetus of their constitution along with their declared and known purposes or intentions. As the power and intensity of person's lust to satisfy his CHW grows, his exposer to others makes it easy to cheat him or to grab his surpluses. To whom we say "others", they should not forget that every individual in the "the others"....himself is not immune from this process. As an individual he will be with "surplus" and victim of $\mathrm{CHW}$, at the same time a good prey for others. 
The people in past and present possess gold with various popular reasons. People use gold in making ornaments to wear, small utensils or other households. Ornaments and other domestic and cosmetic provisions made from gold provide self satisfaction to one for getting distinguished and partly it serves as a capital on hand (as exchange value is ensured). It also serves purpose of getting others attraction, to impress upon others, to exhibit the richness to others etc.

The gold is also retained in the form of coins, biscuits or any other shape of ingot. It is used for various purposes as already discussed above. Various uses of gold are explored also with development of human society. But, at the time of primitive social stage, gold might not find any specific use other than attracting other's attention towards something that might not be available to others so easily, otherwise as a capital of an assured exchange value.

As the society was very simple and founded only on activities that might be counted on fingers for making living, naturally gold did not find any importance other than CHW satisfaction, perhaps there were very few direct uses other than CHW. The society developed then after. Overall characteristics of the gold proved to be more convenient to carry out social activities and remained supportive to socio economical transactions. Various usages of gold were also invented. By the time, other usages became popular, the value of gold as a substance to satisfy CHW, started to get pushed behind the growth of "other usages". This is also discussed in my article "Value of Money".

The journey of gold has always remained in pace matching with development of human society. As primitive man developed knowledge of farming \& horticulture, animal husbandry, fishing, mass collection of jungle products etc, the activities pertaining to events of social transactions and human dealing increased simultaneously. This development explored some further use of gold other than CHW satisfaction. Due to some beautifully favourable characteristics of gold, gold found a vital place in human society. The role of grass root reason of CHW got pushed behind and its reliability in barter process earned an esteemed trust of people. Thus, gold penetrated in the bone marrow of social economic structure. As other parameters, supporting value of gold became front line figures, the original parameter $\mathrm{CHW}$ slowly got pushed into back side. The events for shifting of parameter $\mathrm{CHW}$ in the rear raw happened before such a long time with slowly matching pace with social development that we forgot this prime parameter that constituted first value in gold.

At the same time, new development in human society and its system warranted inevitable processes of barter for the existence of the established social system. The inevitable barter processing for innumerable commodities with various characteristics became plausible with the help of gold only, because, that had won esteemed trust of people. This is the basic reason where gold enjoyed an exceptionally reliable exchange value not in the market or social system but in the hearts of the people of the society. However, its founding parameter (CHW) since its (gold's) infant stage with man still survives with the same potential.

As soon as a social system gets collapsed with any reason, all the parameters (other than CHW) that support the value of gold get vanished. However, parameter due to CHW still survives till the people of the society are hopeful for the stabilization (after a lap of time) of the social system again. Thus, gold is the metal that reasonably and consistently satisfied the CHW in each person of any strata of the society. As this is the fact with almost all the people of the society, gold assured exchange of required commodity, useful substance, securing favour, availing services and possibility to satisfy various needs from others in exchange of gold. This assurance was genuine one and proved to be effective and successful. This assurance won the trust of the people as its untold and unwritten promise for exchange value proved successful without showing any appreciable influence of time, place, season or tenure of ruling. This assurance is the root source of its trustworthiness that made the gold valuable. It is true that gold has enjoyed very long time reputation as "precious metal" since long from past history of mankind to till today, but the CHW is one of the prime parameter that constitutes value (exchange value) in gold.

\section{Its available quantity in nature and subsequently in our social system}

The gold is available at various places and in the form of gold ore or sometimes as pure gold also. The available quantity of gold during any socio economic formation remained at such level that it always maintained its adequate scarcity in the society. At the same time, source of gold availability did not make it scarce to the extent that its recognition remains only within few aristocrat people of the society. The maintenance of balance between scarcity and availability of gold in society at various places of the world has remained more or less stable. This has played a key role for the present status of gold. However, this is more effectively applicable 
to all those societies that, in spite they were established at far distances, they remain in touch with commercial transactions and had some association.

NB: The above observation might not stand true for the European societies and Inca societies when Pesaro discovered them in search of gold in South America. Of course sense of value of gold there in Inca habitations and that of societies of advance world of the time must be different. The essence of saying is that the profile/pattern of the sense of value in gold remains different depending upon the level of socio economic formation of the societies.

Let us hypothetically consider that a man puts one thousand tons of gold in market every day to sell. Its first reaction will be reduction in gold prices. The gentleman continues to sell above quantity with what so ever reduced price he gets. After a couple of days or so, price of gold might equal to that of aluminium. If one ask the reason, most of the veterans in economics will jump to "demand and supply" theory to explain the case of gold price reduced to aluminium price. Here it is not so in grass root. In fact, when gold found available in plenty, even the purpose to get CHW satisfied is also jeopardised along with other all influences founded on being scarce in the society. As this sentiment gets projected indirectly in "demand and supply", it portraits and projects the status of feeling of people with CHW. "Demand and supply" is just like cardiogram that actually projects status of health of heart functioning, it is never a reason.

Today, as we are surrounded by very complex economic system that has evolved with human society, it is difficult to visualize this fact. If we go sufficiently back into past, the scarce availability of gold was one of the causes that satisfied CHW reasonably. Following words from historical facts will justify how gold retained its prestige. Here is the status of aluminium that enjoyed higher status than gold but the status of aluminium collapsed automatically within short time.

"Before the Hall-Héroult process was developed in the late 1880s, aluminium was exceedingly difficult to extract from its various ores. This made pure aluminium more valuable than gold. Bars of aluminium were exhibited at the Exposition Universelle of 1855. Napoleon III of France is reputed to have given a banquet where the most honoured guests were given aluminium utensils, while the others made do with gold."

If aluminium would be that difficult to extract even today, the utensils and ornaments of aluminium might have found place in the life of aristocrat and richest known people only. While as the fact of history and present say that gold never became available in such a quantity that might kill the CHW.

Further to this, it always remained available in adequate quantity to remain in the image of common and majority people. Platinum has some reputation like gold because it also remains scarce with available quantity. However, even today, platinum is not that reputed and acceptable in peoples dealing and transactions as the gold has been.

There are metals much costlier than gold and the availability of such metals in nature and in human society are more scarce that of gold. However, such metal could not acquire the status that gold has won in human society. It is because; gold's status/value in human society is not founded only on single reason because it is scarce, but I should say reason is "it has remained scarce just adequately". The supporting parameters to this value/status of gold are various and each is having its own importance. It is also true that the availability of gold from nature to the society is not that much scarce that it could not reach to the common people. The availability of gold is sufficient that it is affordable to a common man of the society.... may be in small quantity. This advantage permitted recognition of gold to many more people of the society. The availability retained more or less throughout the mankind history since the gold was introduced as a precious metal. While platinum did not enjoy this advantage with enough quantity to become popular in common people. At the same time, it should also be in short quantity to maintain the status of "scarcely available".

While as few metals are much costlier than gold, however, these metals also do not enjoy the status that gold does. This is because these metals are very short in quantity. Its available quantity is not sufficient for activities for transaction and dealing in social systems or social services. However, gold renders such services today due to its adequately available quantity. Secondly gold has grass root recognition to all most, all the people because of its historical association with man, while the subject precious metals are discovered before few decades. So scarce availability helped gold on one part, also it's just adequate availability played a vital role to maintain its popularity and recognition to common people as well as to help in the social transactions. 
But it is also mandatory for him to manage for remaining in public image without long interruption. If he disappears for a longer time from public image or his working strategy keeps him in touch with limited people only, he becomes a legendary one and reputation gets fainted. Likewise, just adequate availability of gold always kept it in the social dealing and transactions by people in day to day life. This boosted its popularity always at high level.

One fact should be accepted while we study the value of gold. The people's choice has fundamental influence; it is not important what an economist believes. It is the people's mind that chooses option whether to trust gold or not and that determines the value in gold. Let us shortly go through an excellent experiment carried out by a journalist, Mr. Gene Weingarten of "Washington Post". The journalist convinced the very famous violin player Joshua Bell to play his best rhythms at a place in Washington from where the people passing by are most likely fan of music and art. However, it was to be played without any advance announcement or canvassing to the people there. It was to be done just other street baggers do. Joshua Bell played for 45 minutes with all his best rhythms with a hat hiding his face. Very rare attention was received, out of those passing by. Most of them did not show any interest nor gave any attention. Two days before his playing in the subway, Joshua Bell sold out at a theatre in Boston and the seats average \$100. The performance was houseful and all the entry sold out within two hours after booking opened. While as during the violin play at Metro terminal, Joshua Bell could collect slightly more than 52 dollars totally in appreciation by passersby.

Above event projects the typical nature of man and his way of choice as well as other parameters that control and influence his choice. However, very long stability in the balance between availability and scarcity of gold, at the same time, assurance in return for re-sale value or its (gold's) prestige in barter constituting exchange value and that too for decades and centuries and more, built a grass root trust in the hearts of the people. This people more or less have remained the same in general behaviour as seen in above example. But, it is a fact that the subject trust has foundation on the balance between scarcity and availability of gold and the same trust is a prime foundation of present value status of gold.

\section{Its innocent and favourable characteristics}

Gold has its own characteristics like other elements and substances. These characteristics are friendly to man. For example, it does not harm to our body with physical touch. It is non-poisonous; do not get corroded in any type of weather effect for years together. Also, ordinarily non reactive with our sweat and water/moisture, perfumes, and other wears we generally use to dress ourselves. It does not lose weight/mass so rapidly either due to wear and tear with ordinary careful handling. Neither it gets dissolved with water or during activities with other ordinary liquids used in public life on body nor gets sublimated at hottest climatic temperature.

Appearance is pleasant and attractive, without any odd, unpleasant odour etc. It is easy to make alloy with copper that is also easily available. With a very minute fraction of amalgamation with copper, its strength and malleability response is favourably positive. This developed characteristic favours the working on gold to shape and make it tough enough to hold the figure and contour it is given. It is not combustible to threat fire hazard, mostly non reactive to all such material that is used in domestic life of the man. Its melting temperature is not that high that special high temperature device is must to melt it to casting, shaping and sizing. This facilitates to ordinary person to work on it. Its hardness, toughness, tensile strength and other characteristics are so friendly that ordinary tools and equipments facilitates to even poor goldsmith to work on it, but at the same time it has also enough strength that the worked-out product might be utilised in day to day life without risk of its breakage or distortion. If not in form of ornament, it might be preserved in any shape or form with smallest space occupation and without risking its loss due to corrosion/decomposition etc. There are still many other characteristics that support the vital and wide acceptance of gold in economic and social life of human society.

\section{Long association with man since or before ancient time}

It is perhaps impossible to find out the date of discovery of gold. It is an empirical discovery. Gold is associated with man since ancient time or before. The long association of gold with man might be judge from following words of history,

Gold artefacts found at the Nahal Kana cave cemetery dated during the 1980s, showed these to be from within the Chalcolithic, and considered the earliest find from the Levant (Gopher et al. 1990). [56] Gold artefacts in the Balkans also appear from the 4th millennium BC, such as those found in the Varna Necropolis near Lake Varna in Bulgaria, thought by one source (La Niece 2009) to be the earliest "well-dated" find of gold artefacts. 
Gold artefacts such as the golden hats and the Nebra disk appeared in Central Europe from the 2nd millennium BC Bronze Age.

While other metals that are more precious than gold has very short association with man. The metals, those are more precious than gold as per present market value, are discovered within last few decays and out of those metals, platinum is the metal that has comparatively longer association with man than other metals that are more precious than gold. However, compare to the period of association of gold with man, platinum's association period is too short one. If we refer the words of history for its (platinum) association with man,

In 1741, Charles Wood (scientist) a British metallurgist found various samples of Colombian platinum in Jamaica, which he sent to William Browning for further investigation. Antonio de Ulloa also credited with the discovery of platinum, returned to Spain from the French Geodesic Mission in 1746 after having been there for eight years. His historical account of the expedition included a description of platinum as being neither separable nor calcinable.

This is because platinum's availability in market realized too late. It was discovered some times in 16th or $17^{\text {th }}$ century while people were exploring new world land and culture prevailed there. Looking to the century of discovery, age of platinum is an infant-age against that of gold as far as reputation with time length is considered. The availability has intense influence on reputation as it indirectly controls CHW. If we go in primitive life or in remote places where people were isolated from present world inhabitation, we may find ornaments from copper as the copper ornaments are capable to satisfy CHW there in the society. The enjoyment of this status by copper metal in primitive social set up is no less than that of gained from gold in present advance society with respect to CHW.

The long association of gold with man has surely given a long term opportunity to gold to get dissolved in the human social system. The social system passed through the evolutions and revolutions. Ultimately, it turned into a human society with complex network of various systems, institutions etc. The close-mesh knitting of various social systems \& institutions, transactions and dealings of people interacting in it, and use of gold in various forms and with various purposes offered vital and favourable environment and opportunities to gold to become a reliable supporting pillar to various dealings and transactions in the social system without which social system cannot run. This opportunity offered gold to get extruded with sufficient depth into human society. This extrusion ultimately reached to such a level/depth and to the extent where economy of the social system could be regulated with the control of quantity of gold. Now it is not easy to replace this status with other substance or alternative so easily. For the first time, advance production system, healthy raw material resources, economical energy sources, advance technology, efficient transportation, most reliable and quick communication and availability of educated, experienced as well as skilled and qualified manpower surfaced a doubt on the status of gold that it enjoys in economics in our society.

However, its long association with man is its one of the vital parameter that fetches gold a value, otherwise, even more precious metals than gold do not have this favour or qualification that gold enjoys.

\section{Easy to recognize and simple ways for quality judgement}

When any substance becomes precious in society, its duplicate also takes birth automatically. The investment behind discovery or invention of duplicate, and its supply network depends on the preciousness of the substance and population strength of typical people with surplus in their hands. The duplicating has concern to all those who cannot afford the cost of real one. At the same time, availability of duplicate enables to control sentimental hysteria of person's lust to stand equally and comparable with those having real one. In simple words, some people get their want satisfied through affordable duplicate means. Act of cheating and duplication is recognized by the law of nature also. We see duplicate snake and butterfly in natural life. However, it is not recognized by social system nor its ethical theory supports it.

We find people in the society that makes their living on cheating and treason. Duplication and adulteration in gold has remained a source of making living for many in human society. This needs provision to get protected from the victimization of such duplication or adulteration while transacting with gold. There are simple and reliable methods and tests that might reveal the status of purity of gold at any time. Even, it is also simple to make out the nearest accurate judgement for the percentage of amalgamation done with other metals. Neither such test needs any costly and complicated instruments of testing nor is it lengthy or complex by procedure. A well experienced goldsmith is able to judge the purity of gold by touch and press only, making a scratch on polished granite stone and by other simple tests. The requirement of verification of purity of gold due to threat 
of adulteration in day to day transactions in society and availability of simple and reasonably reliable various methods for the same, furnished one more qualification to gold for becoming most popular precious metal.

Other metals, more precious than gold do not have this advantage. Its testing is very complicated or needs specific apparatus, its melting temperature is high enough that makes it inconvenient with simple fire device. It is either not friendly with man or reacts with moisture, skin etc. Reacts with oxygen in atmosphere, sweat of man, and bears other radical characteristics adverse to man's interest. These characters did not allow them to find open and wide spread usage in society its transactions while as gold did make it. Due to easy and friendly quality test, people found adequate security of their interest in the gold with minimum expenditure on quality testing. This is a vital support to gold for becoming most popular and versatile in social transactions, and that ultimately turned out to its popular acceptability.

\section{Gold has recognition in almost all the parts of the world where human species}

We are aware that there are few other metals more precious than gold (e g Plutonium, Platinum, etc). As discussed above, gold has long history of association with man. This course of history allowed gold to migrate to other places of world with migrating people to human habitations where gold was still to be discovered. The migrated people mixed with the new habitation and gold was introduced there also. Further to this, availability of gold from nature on this planet earth is at more places compare to other precious metals. The gold mines at multiple places also helped in popularity. When gold acquired a wide spread popularity in transaction and dealing, it might become one of the most reliable substance of exchange value in barter. At the same time proven assurance of stability of its exchange value enhanced the popular confidence in people. Further to this, its persistent scarcity against reasonable availability more or less maintained stability in all the populated areas of the world where it was introduced or discovered independently. But it is a matter of fact that gold remained popular and recognized in almost all the parts of the world. This wide spread recognition is one of the prime parameter that supports the present value status of gold.

\section{Summarising Result}

We have discussed how human weakness (CHW) is linked with the first sense of value in gold. It is also discussed that the influence of other four parameters and evolution of human society slowly transformed into an assurance of exchange value in gold. As such value is founded on use value only and value is independent of exchange value. When we know that present value status of gold in people's mind as well as its potential influence on economic net work of present society is founded on its reliability as well as assurance of exchange value of gold, we should never forget the basic parameters that influence the determination of exchange ratio in an exchange process. I simply list out the influencing parameters that determine the exchange ratio in an exchange.

The list of the influencing parameters:

1. Quantum of labour and cost sustained on the commodities in their possession

2. Lack of adequate knowledge about commodity in exchange process:

3. Potential of affinity (propensity) in either party to satisfy the subject need:

4. Possibility to sustain without subject exchange:

5. Knowledge about alternate source of availability of the commodities in exchange process:

6. Vision for future prediction:

7. An exchange for recovery purpose:

8. An exchange under acquaintance, relation and under-impression:

9. Process of exchange where on either side more than one party negotiates:

10. An exchange where either or both parties have poor recognition of the quality/specifications of the commodities in exchange:

11. An exchange under adverse or favourable circumstances and helplessness:

12. An exchange carried out in artificial environment:

13. Lack of adequate information with either or both parties:

14. Influence of misleading propaganda and rumour on exchange process:

15. Exchange under threat and pressure:

16. Exchange with a purpose to oblige or for ethical consideration etc:

17. Exchange with a purpose to acknowledge an appreciation by either party:

18. Different hidden intentions to be upheld through the process of exchange:

19. Process of exchange carried out under instigation by others: 
20. Process of exchange carried out just for showmanship:

If we sharply analyse the nature of each parameter in above list, it will realise that all the parameters are linked with various human characteristics also. When the process of determination of an exchange ratio during an exchange process is influenced by above parameters, and vital role of gold in net work of economics of our society is founded on its (of gold) exchange value, it is but natural that the assured reliance on gold ultimately gets founded on the reliability of social systems, health of social institutions and quality standard of people's morality.

\section{Conclusions}

There are diamonds having far high value compare to gold. In spite, diamonds could not make its status in human society as gold has done it. If one goes through above discussed parameters, he will immediately realize where the diamonds are missing. However, I cite one example that might give a glimpse of weakness in the value of gold. Everyone will agree that there must be minimum two persons in existence on this planet Earth to sense the value in gold, but it is not the case with a banana or bread. Banana or bread is valuable even if one person exists on this planet Earth. An existence of human society is must for the, so called value of gold (in fact it is exchange value). This is the fundamental difference. That is why I firmly believe that gold has exchange value, otherwise gold has no value in general sense. I do agree that wherever gold and its compositions are used to satisfy respective need, the gold has value against the subject need. But if we talk about value of gold in the sense of general reputation of gold, it is exchange value only. The esteemed trust in the heart of the people founded on the above six reasons has earned gold a typical prestige in the market of social transaction and the potential of the prestige creates a mock impression of value in gold, otherwise, it is an exchange value. As exchange value depends on various influencing parameters (listed above) ultimately the sense of value in gold always creates a dilemma among economist as well as among common people depending upon social circumstances. But it is, fact that sense of value in gold is.... in fact.... a sense of assurance of exchange value. Exchange value is always floating as it depends on various parameters as seen above. That is why realization of our sense of value in gold (exchange value) is totally founded on quality level of social systems and their functioning, health of social institutions and level of people's moral.

\section{Reference}

Menger, C. (2007). Principles of Economics. Ludwig von Mises Institute, Auburn, Ala, USA. Retrieved from: http://austrian-library.s3-website-us-east-1.amazonaws.com/books/ Carl\%20Menger/Principles\%

20of\%20Economics.html.

2. Whitaker, J. (2001). Henry George, John Stuart Mill and Adam Smith. The American Journal of Economics and Sociology, pp. 11-24.

3. Documentaries programme on wild life on Discovery channel. Retrieved from: http://www.bbc.co.uk/ nature/collections.

4. Mackellar, J. (2013). Participant observation at events: theory, practice and potential. International Journal of Event and Festival Management, pp. 1-18.

5. Biography of Winston Churchill by Trukhanovesky. Retrieved from: https://www.biography.com/people/winston-churchill-9248164

6. Thomas, Benjamin P. (1979). Abraham Lincoln. Modern Library. Retrieved from: https://www. goodreads.com/book/show/919473.Abraham_Lincoln.

7. Mediaeval History of Europe by Moon and Ray. Retrieved from: https://www.britannica.com/topic/ history-of-Europe/The-Middle-Ages

8. Sanders Vivienne (2003). Race Relations in the USA since 1900 (Access to History). Retrieved from: https://books.google.com.ua/books/about/Race Reltions in the USA Since 1900.html?id=v8ZXHAAAC

AAJ\&redir_esc $=\mathrm{y}$

9. Sevruk, V. (1974). How Wars End: Eye-witness Accounts of the Fall of Berlin. History, p. 27.

10. Zhukov, G. (1985). Reminiscences and Reflections. Progress Publishers. pp. 1-16.

11. Dickens, Ch. (1972). Scenes from the Pick Wick papers. Published by Madras Macmillan, p. 179.

12. Rothschild, J. (1974). East Central Europe Between the Two World Wars. History of East Central Europe . University of Washington Press, 9, pp. 265

13. The Travels of Marco Polo - Revised by Marsden's Translation and Edited with an Introduction by Manuel Komroff. Printed in the United States of America Manufacturing by the Maple-Vail Book Manufacturing Group. 
14. Mr. Gene Weingarten. Washington Post. Retrieved from: https://www.washingtonpost. com/lifestyle/magazine/ gene-weingarten-thank-you-for-this-honor--but-what-were-you-thinking/2017/06/

12/c07bb0d0-4249-11e7-9869-bac8b446820a story.html?utm term=.d0d33b544f2d

15. Historical quotes. Retrieved from: https://en.wikipedia.org/wiki/Portal:History.

Weber, Max. Economy and Society. Retrieved from: https://archive.org/stream/MaxWeberEconomy AndSociety/MaxWeberEconomyAndSociety djvu.txt.

17. Weber, Th. (2007). Our Friend The Enemy, 360 p.

Man Karlfried Durkheim (1988). Hara the Vital Centre of Man. pp. 1-109. Retrieved from: https://terebess.hu/zen/ mesterek/Hara.pdf.

19. Foucault M. Discipline and Punish. Retrieved from: https://monoskop.org/images/4/43/ Foucault_Michel_Discipline_and_Punish_The_Birth_of the Prison_1977_1995.pdf. 